\title{
Safety and efficacy of minimal biliary sphincterotomy with papillary balloon dilation (m-EBS+EPBD) in patients using clopidogrel or anticoagulation $\square$
}

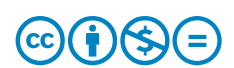

\author{
Authors \\ Shaffer R. S. Mok , Murtaza Arif², David L Diehl², Harshit S Khara², \\ Henry $\mathrm{C} \mathrm{Ho}^{1}$, Adam B Elfant ${ }^{1}$ \\ Institutions \\ 1 Cooper Medical School of Rowan University, MD Anderson \\ Cancer Center at Cooper, 501 Fellowship Rd, Suite 101, Mt. \\ Laurel, NJ 08054 \\ 2 Geisinger Health Systems, Department of Gastroenterology and \\ Nutrition, 100 N Academy Ave, Danville, PA 17822
}

submitted 26.7.2016

accepted after revision $\quad 10.10 .2016$

Bibliography

DOI http://dx.doi.org/10.1055/s-0042-120225 |

Endoscopy International Open 2017; 05: E157-E164

(c) Georg Thieme Verlag KG Stuttgart · New York

ISSN 2364-3722

Corresponding author

Shaffer R. S. Mok, MD, MBS, Cooper Medical School of Rowan

University, MD Anderson Cancer Center at Cooper, 501 Fellowship

Rd, Suite 101, Mt. Laurel, NJ USA 08054

Fax: (856) 642-2134

mok.shaffer@gmail.com

\begin{abstract}
Background and study aims Endoscopic retrograde cholangiopancreatography (ERCP) with endoscopic biliary sphincterotomy (EBS) or endoscopic papillary balloon dilation (EPBD) are common techniques of biliary decompression. Potential risks include gastrointestinal hemorrhage, which can be increased by antiplatelet agents, anticoagulants (AC) and/or novel oral anticoagulants (NOACs) (ie. apixaban, dabigatran and rivaroxaban).

The study aim is to evaluate the safety/efficacy of an alternative technique, minimal-EBS plus EPBD (m-EBS +EPBD), in individuals for whom clopidogrel, AC, and/or NOACs cannot be interrupted due to high cardiovascular or thromboembolic risk.

Patients and methods Patients undergoing m-EBS +EPBD while taking clopidogrel and/or AC were retrospectively evaluated at two United States tertiary care centers for efficacy, GIB and procedurerelated, cardiovascular and thromboembolic adverse events (AE).

Results Ninety-five patients were identified [ $55=$ clopidogrel and $45=$ AC $(31.1 \%$ NOACs $)]$. The main indication for ERCP was choledocholithiasis (34\%). $100 \%$ clinical improvement and $97.9 \%$ endoscopic success were found. The incidence of AE was $5.3 \%$. There was a $4.2 \%$ incidence of gastrointestinal hemorrhage ( 2 cases requiring endoscopic intervention). Both severe gastrointestinal hemorrhages also experienced the cases of post-ERCP pancreatitis, and $2 / 3$ of cholangitis (all aspirin $+A C$ ). There was 1 cardiovascular event (non-ST elevation myocardial infarction), and no thromboembolic events.

Conclusions Minimal-EBS +EPBD is an effective and safe therapy with an incidence of gastrointestinal hemorrhage of $4.2 \%$, (2.1\% requiring endoscopic intervention), for patients on clopidogrel and/or AC, with a high risk for cardiovascular/thromboembolic events.
\end{abstract}

\section{Introduction}

Endoscopic retrograde cholangiopancreatography (ERCP) with endoscopic biliary sphincterotomy (EBS) or endoscopic papillary balloon dilation (EPBD) are safe and effective treatments for patients requiring urgent biliary drainage $[1-8]$. EBS has a small risk of post-sphincterotomy bleeding, and it was hoped that EPBD might decrease this risk. Several case series from Asia used EPBD without EBS for stone clearance, showing equal efficacy and lower rates of gastrointestinal hemorrhage [914]. Despite this sentiment, the risk of post-ERCP pancreatitis with EPBD alone is quite high when reproduced in the United States (US) [15]. The technique of minimal EBS in combination with EPBD was developed to try to achieve the benefits of EPBD without additional risk of post-ERCP pancreatitis [16-19]. Studies evaluating this technique have demonstrated no in- creased risk of post-ERCP pancreatitis, while lowering the risk of post-sphincterotomy bleeding as compared with EBS alone [16-19].

An increasing number of patients who require ERCP and EBS are taking antiplatelet medications and anticoagulants (AC), and many cannot safely stop these agents due to high risk of cardiovascular or thromboembolic events. [20-22]. Data are conflicting regarding the risk of gastrointestinal hemorrhage after biliary sphincterotomy in the presence of these medications [23-29]. There is also a paucity of data regarding several novel oral anticoagulants (NOACs) such as rivaroxaban (Xarelto, Janssen), apixaban (Eliquis, Bristol-Myers Squibb), and dabigatran (Pradaxa, Boehringer Ingelheim) as well as uncertainty about these high-risk procedures in patients on combination therapy. 


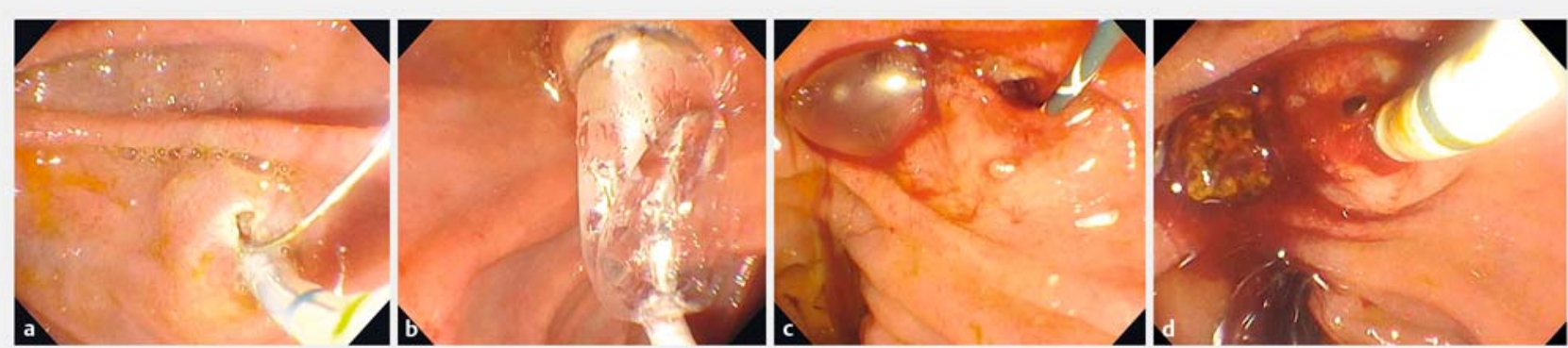

- Fig. 1 This figure demonstrated the pictorial step-by-step approach to minimal-biliary sphincterotomy (m-EBS) + endoscopic papillary balloon dilation (EPBD) for a patient on clopidogrel and aspirin. a m-EBS, b EPBD, c post-intervention, $\mathbf{d}$ stone extraction.

According to expert guidelines, EPBD appears safer than EBS in the setting of coagulopathy, $A C$ and antiplatelet agents. As a result, EPBD is recommended in lieu of EBS, when AC and antiplatelet agents cannot be discontinued [30-37]. Given the increased risk of post-ERCP pancreatitis with EPBD alone and the decreased risk of gastrointestinal hemorrhage with m-EBS + EPBD, when compared with EBS alone, it may be possible to utilize this combined strategy for individuals at increased risk for gastrointestinal hemorrhage.

The aim of this study was to evaluate the safety and efficacy of limited sphincterotomy ("minimal-EBS", m-EBS) plus EPBD in patients undergoing ERCP for whom clopidogrel, AC, and/or NOACs cannot be interrupted due to high cardiovascular or thromboembolic risk. We predicted that m-EBS + EPBD in these patients would result in a post-procedural risk of gastrointestinal hemorrhage similar to published risk in patients undergoing ERCP with EBS but not on these medications.

\section{Patients and methods}

\section{Sample selection}

We performed a retrospective analysis of high-risk patients on either clopidogrel or AC who could not safely stop these medications due to elevated cardiovascular/thromboembolic risk and who underwent therapeutic ERCP at 2 tertiary care centers (Cooper University Hospital in Mount Laurel, NJ and Geisinger Medical Center in Danville, PA) from October 2001 until August 2015. Both inpatient and outpatient ERCPs were included. This technique was performed based upon preliminary experience by endoscopists at both institutions. All patients had undergone a minimal EBS (m-EBS), defined as EBS $<4 \mathrm{~mm}$ or under one-third of the diameter of the papilla in cases with a large intra-duodenal segment ( $\vee$ Fig. 1 ) followed by an EPBD ( $\vee$ Video 1). EBS size was measured by comparing the size of the $\mathrm{m}$ EBS with the mid portion of a bowed sphincterotome and all $\mathrm{m}$-EBS were performed using standard endocut I effect 2, cutting duration 3, cutting interval 3 (Erbe Incorporated, Tübingen, Germany). EPBD was performed for at least one minute using mostly biliary balloons and rarely an esophageal balloon [38].

Selection of balloon size was determined based upon the maximal diameter of the bile duct, allowing for facilitation of appropriate endotherapy. The rationale behind this approach was based upon prior studies evaluating m-EBS +EPBD, when compared to EBS alone, as well as data from prior studies evaluating EPBD alone [9-19]. Because prior studies on m-EBS+ EPBD have demonstrated a lower incidence of post-sphincterotomy bleeding, and studies in the United States have demonstrated a high incidence of post-ERCP pancreatitis, we chose to evaluate the technique of $\mathrm{m}$-EBS + EPBD for patients undergoing ERCP, who were on $A C$ and/or clopidogrel.

All patients were taking aspirin in combination with either clopidogrel and/or AC during the time of their procedure. Anticoagulants evaluated included enoxaparin, warfarin, and NOACs such as apixaban, dabigatran, and rivaroxaban. Patients who used warfarin demonstrated a therapeutic INR and received no fresh frozen plasma to counteract this drug's effects. All subjects who did not undergo m-EBS + EPBD during their ERCP, and who were not on clopidogrel, $A C$ and/or NOACs, were excluded. Patients were also excluded if they were aged $<18$ years, pregnant, had undergone precut sphincterotomy, had a supratherapeutic INR, had any missing data point, or if they did not have documented follow up after the ERCP to confirm or exclude gastrointestinal hemorrhage ( $>$ Fig. 2). Data were collected on patient demographics, comorbid medical conditions,

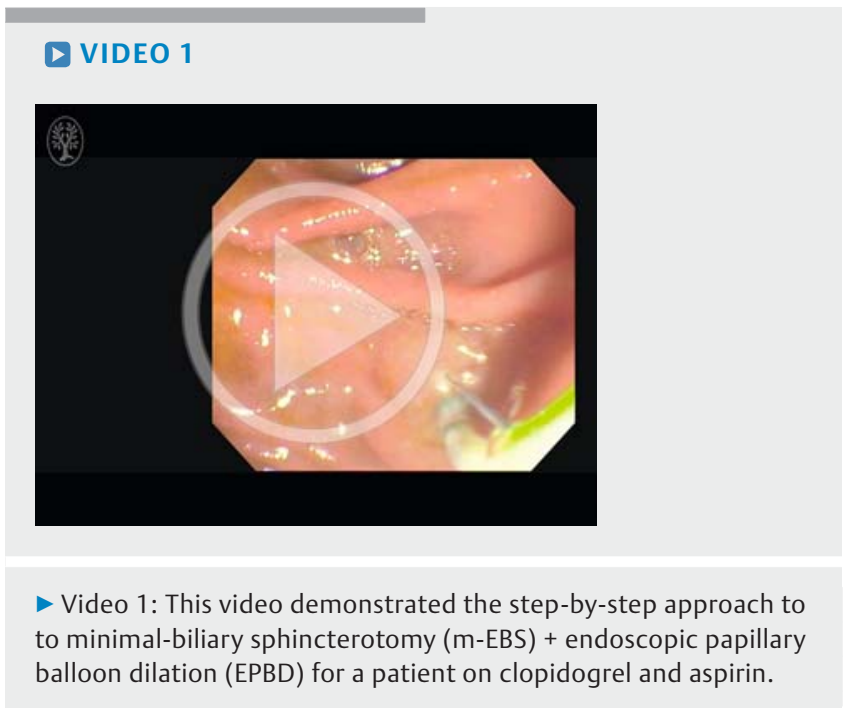




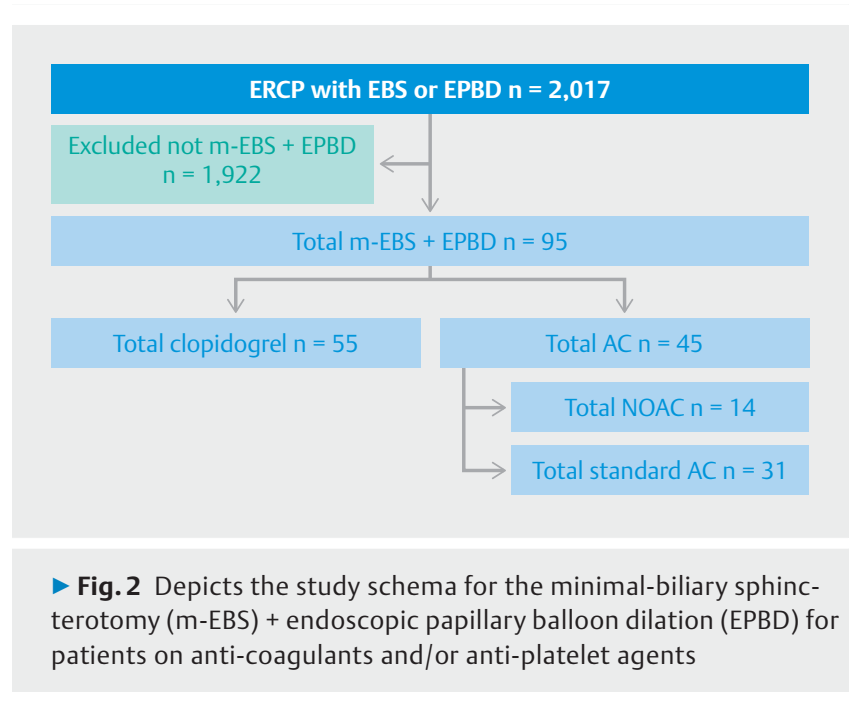

use of aspirin, nonsteroidal anti-inflammatory drugs (NSAIDS), clopidogrel, AC and NOACs.

Data regarding pre-procedural labs (CBC, PT/INR), size of the dilation balloon, procedural details, and procedure-related adverse events (AEs) and mortality were captured. All ERCPs were performed by 1 of 4 experienced therapeutic endoscopists, typically with either a postgraduate year (PGY) 6-gastroenterology fellow or PGY7 therapeutic endoscopy fellow. No patients received rectal indomethacin prophylaxis as this was not the standard practice at 1 institution and the other did not have patients at high risk or post-ERCP pancreatitis [11]. Endoscopic success was defined as relief of obstruction (including calculus extraction, when applicable) and reversal of the etiology for which the procedure was performed. All patients requiring stent placement received a plastic stent. No patients received a self-expanding metal stent, as all malignant strictures treated either were surgical candidates or had a life expectancy that would not necessitate SEMS placement.

All patients had determination of hemoglobin, platelet count, prothrombin time, and international normalized ratio (INR) prior to their ERCP. The hemoglobin was also checked after the procedure during follow up and/or hospital admission, when applicable. No patients received blood products, vitamin $\mathrm{K}$, or prothrombin complex to normalize their platelet count and/or INR prior to ERCP. Study follow up was obtained via review of medical records. For the study institutions, follow up was secured by the following means: telephone call 24 hours after ERCP or scheduled office visit with the physician performing the ERCP. Patients with any potential procedure-related complications were instructed to contact the on-call service and proceed to the study institution's emergency department when required, as is the standard practice at both institutions. All post-procedural patient discussions were documented via the electronic health record system. Patients who were sent to another institution for post-procedure medical care were instructed to have the treating hospital contact the on-call service for the institution at which the ERCP was performed.

\section{Outcomes}

The primary outcome was gastrointestinal bleeding, defined as presence of melena, hematochezia, hematemesis, unexplained drop in hemoglobin of $>2 \mathrm{~g} / \mathrm{dL}$ from baseline, or need for packed red blood cell (PRBC) transfusion. Procedure-related gastrointestinal hemorrhage was classified as immediate (intra-procedure), early ( $<48$ hours after the procedure) or delayed ( $\geq 48$ hours to 2 weeks post-ERCP) [39]. Severe gastrointestinal hemorrhage was identified on the basis of the requirement for PRBC transfusion, need for endoscopic hemostasis, or need for vascular embolization. Secondary outcomes included frequency of post-ERCP pancreatitis, perforation, need for repeat ERCP, infection, aspiration, cardiovascular event (acute coronary syndrome, need for percutaneous coronary intervention, cardiac arrest, arrhythmia), thromboembolic events (stroke, pulmonary embolism, deep venous thrombosis), and death.

\section{Statistical analysis}

Means, frequencies, and percentages of the study cohort are presented. Statistical significance was based on a $P$ value of 0.05. All statistical analysis was carried out using SAS v9.4 (SAS Institute, Cary, NC).

\section{Results}

\section{Sample characteristics}

A total of 95 ERCPs were performed using the m-EBS + EPBD technique. Mean patient age was 69 (standard deviation of 12.5 years), $56 \%$ were men, and $77 \%$ Caucasian. All patients were at high risk for stopping clopidogrel and/or AC prior to their procedure. The most common high-risk indication (present in $42 \%$ ) was atrial fibrillation with associated risk factors (valvular heart disease, prosthetic heart valve, active congestive heart failure, left ventricular ejection fraction $<35 \%$, a history of thromboembolic event, hypertension, diabetes mellitus, or age $>75$ years. Additional high-risk factors included; non-stented coronary artery disease (42\%), presence of a drug-eluting coronary stent $<1$ year $(32 \%)$, bare metal coronary stent $<6$ months ( $0 \%)$. The mean pre-procedural hemoglobin was 11.4 and mean post-procedural hemoglobin 11.2. The mean pre-procedural INR was 1.6 and platelet count 227.2.

One hundred percent of patients were on aspirin in combination with another agent. There were no patients included who were on aspirin, clopidogrel or AC alone. Fifty-eight percent of patients were on clopidogrel of whom $100 \%$ were also on aspirin. A total of $47 \%$ of patients were on AC including $31 \%$ on NOACs $(n=14), 64 \%$ on warfarin $(n=29)$ and $4 \%$ on enoxaparin $(n=2)$. Five percent of patients were on AC, aspirin and clopidogrel $(n=5)$. Finally, $7.4 \%$ of patients were on NSAIDs ( $>$ Table 1).

\section{Endoscopic characteristics and outcomes}

The main indication for ERCP was choledocholithiasis (37\%); other indications included abnormal imaging (17\%), indeterminate biliary stricture $(31 \%)$, cholangitis (7\%), stricture due to 
- Table 1 Characteristics of patients who underwent m-EBS + EPBD; demographics, medical conditions, laboratory values and medications.

\begin{tabular}{|c|c|c|}
\hline \multirow[t]{2}{*}{ Mean Age (years) } & & 69 \\
\hline & & $\%$ of total \\
\hline \multirow[t]{2}{*}{ Gender } & Male & $53(56 \%)$ \\
\hline & Female & $42(44 \%)$ \\
\hline \multirow[t]{4}{*}{ Race } & Caucasian & $73(77 \%)$ \\
\hline & African american & $13(14 \%)$ \\
\hline & Hispanic & $8(8 \%)$ \\
\hline & Asian & $1(1 \%)$ \\
\hline \multirow{13}{*}{$\begin{array}{l}\text { Cardiovascular } \\
\text { disease }\end{array}$} & CAD & $70(74 \%)$ \\
\hline & Non-PCI & $40(42 \%)$ \\
\hline & $\mathrm{PCl}$ & $30(32 \%)$ \\
\hline & CABG & $1(1 \%)$ \\
\hline & ACS & $0(0 \%)$ \\
\hline & Afib & $40(42 \%)$ \\
\hline & HTN & $95(100 \%)$ \\
\hline & DM & $70(74 \%)$ \\
\hline & $\mathrm{CHF}$ & $10(11 \%)$ \\
\hline & DVT & $9(10 \%)$ \\
\hline & PE & $5(5 \%)$ \\
\hline & PVT & $1(1 \%)$ \\
\hline & Valve replacement & $8(8 \%)$ \\
\hline Cirrhosis & & $10(11 \%)$ \\
\hline Chronic renal failure & & $5(5 \%)$ \\
\hline Prior GIB & & $2(2 \%)$ \\
\hline $\begin{array}{l}\text { Mean hemoglobin } \\
\text { pre-procedure ( } \mathrm{g} / \mathrm{dL})\end{array}$ & & $11.4(7.6-14.6)$ \\
\hline $\begin{array}{l}\text { Mean hemoglobin } \\
\text { pre-procedure ( } \mathrm{g} / \mathrm{dL})\end{array}$ & & $11.2(6.2-15.0)$ \\
\hline $\begin{array}{l}\text { Mean INR pre- } \\
\text { procedure }\end{array}$ & & $\begin{array}{c}1.6(1-3.8) \\
12.3(2.1-3.8)\end{array}$ \\
\hline $\begin{array}{l}\text { Mean platelet count } \\
\text { pre-procedure }\end{array}$ & & $227.2(45-621)$ \\
\hline
\end{tabular}

chronic pancreatitis (3\%), biliary pancreatitis ( $2 \%$ ) and bile leak, pancreaticolithiasis and sclerosing cholangitis (all 1 each). The mean size of EBS was $3.4 \mathrm{~mm}$ and mean EPBD size $8.0 \mathrm{~mm}$ ( $>$ Table 2).

There was technical success in $98 \%$ of patients and relief of obstruction in $92 \%$. A calculus was extracted in 49 patients and ductal clearance achieved in 48 , as several patients underwent ERCP for a different indication and calculi were found at the time of cholangiogram. A biliary stent was placed in 33 patients and lithotripsy done in $6(6 \%)$. The pancreatic duct was injected in 19 patients and a stent placed in the pancreatic duct in 13, all

\begin{tabular}{|c|c|c|}
\hline \multicolumn{3}{|l|}{ Medications } \\
\hline NSAIDS & & $7(7 \%)$ \\
\hline Total ASA & & $95(100 \%)$ \\
\hline \multirow{3}{*}{$\begin{array}{l}\text { Total ASA + } \\
\text { clopidogrel }\end{array}$} & & $55(58 \%)$ \\
\hline & ASA + clopidogrel only & $50(53 \%)$ \\
\hline & ASA + clopidogrel + AC & $5(5 \%)$ \\
\hline Total ASA + AC & & $45(47 \%)$ \\
\hline \multirow[t]{3}{*}{ Standard $A S A+A C^{2}$} & Total & $31(33 \%)$ \\
\hline & ASA + enoxaparin & $2(2 \%)$ \\
\hline & ASA + warfarin & $29(31 \%)$ \\
\hline \multirow[t]{4}{*}{$\mathrm{ASA}+\mathrm{NOAC}^{3}$} & Total & $14(15 \%)$ \\
\hline & ASA + apixaban & $2(4 \%)$ \\
\hline & ASA + dabigatran & $3(7 \%)$ \\
\hline & ASA + rivaroxaban & $9(10 \%)$ \\
\hline \multicolumn{3}{|c|}{ 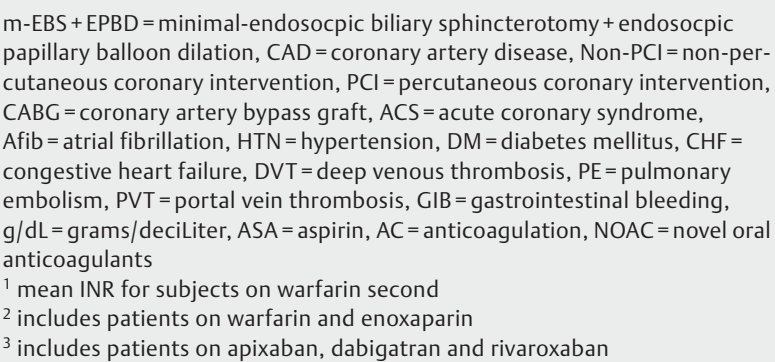 } \\
\hline
\end{tabular}

of whom underwent ERCP for a pancreatic as well as a biliary indication. All endoscopic parameters are summarized in $\downarrow \mathbf{T a}$ ble 2 .

Twelve percent of patients required additional biliary-specific ERCP. Seven developed elevated LFT again after the index ERCP, of which 3 were caused by choledocholithiasis and cholangitis (both $3 \%$ ). Of the 3 patients who had cholangitis/choledocholithiasis, 2 also had gastrointestinal hemorrhage. The remaining 1 patient had no clear etiology for the elevated LFTs. These results are summarized in $>$ Table 3 .

\section{Incidence of bleeding after m-EBS + EPBD}

Four patients (4\%) developed gastrointestinal hemorrhage presenting with a drop in $\mathrm{Hgb}$ by at least $2 \mathrm{~g} / \mathrm{dL}$, and melena ( $>\mathrm{Ta}$ ble 3 ). Two of these patients were on aspirin + clopidogrel, 1 on aspirin + warfarin and the last on aspirin + rivaroxaban. The balloon size of the patients with gastrointestinal hemorrhage who were on clopidogrel was $12 \mathrm{~mm}$ and $6 \mathrm{~mm}$. EPBD size was $12 \mathrm{~mm}$ and $8 \mathrm{~mm}$ for patients who were on $A C$ and developed gastrointestinal hemorrhage. Two patients $(2 \%)$ required blood transfusion ( 2 units of PRBC each and 3 required repeat endoscopy. One of these patients had undergone prior biliary stent placement (plastic 10 French). On repeat endoscopy done to investigate bleeding, 1 patient had no visible source of bleeding (aspirin + clopidogrel), 1 had epinephrine injection into a bleeding sphincterotomy site with endoclip placement (aspirin + warfar- 
- Table 2 Endoscopic procedure characteristics and success of patients who underwent mEBS + EPBD.

\begin{tabular}{|c|c|c|}
\hline & & $\%$ of Total \\
\hline Mean EBS (mm) & & $3.4(2-4)$ \\
\hline \multirow[t]{7}{*}{ EPBD Size $(\mathrm{mm})$} & Mean & 8.0 \\
\hline & 4 & $9(10 \%)$ \\
\hline & 6 & $21(22 \%)$ \\
\hline & 8 & $36(38 \%)$ \\
\hline & 10 & $22(23 \%)$ \\
\hline & 12 & $6(6 \%)$ \\
\hline & 15 & $1(1 \%)$ \\
\hline \multirow[t]{9}{*}{ Intervention } & Clinical improvement & $95(100 \%)$ \\
\hline & Endoscopic success & $93(98 \%)$ \\
\hline & Relief of obstruction & $87(92 \%)$ \\
\hline & Calculus extraction & $49(52 \%)$ \\
\hline & Ductal clearance & $48(51 \%)$ \\
\hline & Biliary stent & $33(35 \%)$ \\
\hline & Lithotripsy & $6(6 \%)$ \\
\hline & PD injection & $19(20 \%)$ \\
\hline & PD stent & $13(14 \%)$ \\
\hline
\end{tabular}

$m-E B S+E P B D$, minimal-endoscopic biliary sphincterotomy + endoscopic papillary balloon dilation; $\mathrm{Cl}$, confidence interval; LFT, liver function tests; PSC, primary sclerosing cholangitis; PD, pancreatic duc

in) and 1 epinephrine injection with fully covered SEMS placement for tamponade (aspirin + rivaroxaban). All interventions led to resolution of bleeding. The fourth patient did not undergo repeat endoscopy and had no significant decrease in $\mathrm{HgB}$ and was discharged from the emergency department (aspirin + clopidogrel). No patient had additional reported melena during 3 month follow-up. These results are shown in $>$ Table 3.

\section{Secondary outcomes}

Post-ERCP pancreatitis was found in $2 \%$ of patients (both in patients with gastrointestinal hemorrhage). The size of EPBD was $6 \mathrm{~mm}$ and $12 \mathrm{~mm}$ for the patients that developed Post-ERCP pancreatitis. There were no perforations. Infections occurred in $5 \%$ ( 3 cholangitis, 1 health care-associated pneumonia and 1 catheter-related blood stream infection). All reported deaths $(n=8)$ occurred as a sequela of the patient's underlying cancer or while the patient was in hospice care. There were no deaths related to complications from ERCP, cholangitis or gastrointestinal hemorrhage. There were no thromboembolic events and 1 cardiovascular event, described as a non-ST elevation myocardial infarction. This patient presented 90 days after the index ERCP and the cardiac catheterization in this patient showed no lesion requiring percutaneous coronary intervention. All secondary outcomes are summarized in $\mathbf{\triangleright}$ Table $\mathbf{3}$.
- Table 3 Incidence of gastrointestinal bleeding, adverse events and need for repeat ERCP after $m E B S+E P B D$.

\begin{tabular}{|c|c|c|c|}
\hline & & & $\%$ of total \\
\hline \multirow[t]{20}{*}{$\begin{array}{l}\text { Adverse } \\
\text { events }\end{array}$} & Total & $\begin{array}{l}\text { Procedure- } \\
\text { related }\end{array}$ & $5(5 \%)$ \\
\hline & GIB & Total & $4(4 \%)$ \\
\hline & & Severe & $2(2 \%)$ \\
\hline & & $\begin{array}{l}\text { Intra- } \\
\text { procedural }\end{array}$ & $0(0 \%)$ \\
\hline & & Immediate & $0(0 \%)$ \\
\hline & & Delayed & $4(4 \%)$ \\
\hline & Presentation & Melena & $4(4 \%)$ \\
\hline & & Hematochezia & $0(0 \%)$ \\
\hline & & Hematemesis & $0(0 \%)$ \\
\hline & & $\begin{array}{l}\text { Drop HgB } \\
>2 \mathrm{~g} / \mathrm{dL}\end{array}$ & $1(1 \%)$ \\
\hline & PRBC transfusion ${ }^{1}$ & & $2(2 \%)$ \\
\hline & Intervention ${ }^{1}$ & & $3(3 \%)$ \\
\hline & & Epinephrine $^{1}$ & $2(2 \%)$ \\
\hline & & Clip $^{2}$ & $1(1 \%)$ \\
\hline & & Stent ${ }^{3}$ & $1(1 \%)$ \\
\hline & $\begin{array}{l}\text { Post-ERCP } \\
\text { pancreatitis }\end{array}$ & & $2(2 \%)$ \\
\hline & CV event & & $1(1 \%)$ \\
\hline & TE event & & $0(0 \%)$ \\
\hline & Death & Overall & $8(8 \%)$ \\
\hline & & $\begin{array}{l}\text { Procedure- } \\
\text { related }\end{array}$ & $0(0 \%)$ \\
\hline \multirow{8}{*}{$\begin{array}{l}\text { Need for } \\
\text { repeat } \\
\text { procedure }\end{array}$} & Total & $23(24 \%)$ & $\%$ of Total \\
\hline & Stent extraction & $12(52 \%)$ & $13 \%$ \\
\hline & $\begin{array}{l}\text { Total requiring } \\
\text { biliary Intervention }\end{array}$ & $11(48 \%)$ & $12 \%$ \\
\hline & Elevated LFT & 7 & $7 \%$ \\
\hline & $\mathrm{GIB}^{4}$ & 3 & $3 \%$ \\
\hline & Choledocholithiasis $^{4}$ & 3 & $3 \%$ \\
\hline & Cholangitis $^{4}$ & 3 & $3 \%$ \\
\hline & Need for biopsies & 1 & $1 \%$ \\
\hline \multicolumn{4}{|c|}{$\begin{array}{l}\text { m-EBS + EPBD, minimal-endoscopic biliary sphincterotomy+endoscopic } \\
\text { papillary balloon dilation; Cl, confidence interval; GIB, gastrointestinal } \\
\text { bleed; HgB, hemoglobin; PRBC, packed red blood cells; ERCP, endoscopic } \\
\text { retrograde cholangiopancreatography; CV, cardiovascular; TE, thromboem- } \\
\text { bolic; LFT, liver function testing } \\
{ }^{1} \mathrm{ASA}+\text { warfarin and ASA + rivaroxaban } \\
{ }^{2} \mathrm{ASA}+\text { warfarin } \\
{ }^{3} \mathrm{ASA}+\text { rivaroxaban } \\
{ }^{4} 3 \text { Patients underwent repeat endoscopy for GIB, choledocholithiasis, and } \\
\text { cholangitis }\end{array}$} \\
\hline
\end{tabular}




\section{Discussion}

In this multicenter study of 95 patients at high risk for cardiovascular/thromboembolic events necessitating continued clopidogrel and/or AC, we demonstrated that m-EBS+EPBD was both safe and effective for management of biliary tract diseases. While continuing both clopidogrel and AC, patients who underwent $\mathrm{m}$-EBS +EPBD had a $4 \%$ gastrointestinal hemorrhage rate, $2 \%$ severe gastrointestinal hemorrhage rate, with $100 \%$ clinical improvement and $98 \%$ endoscopic success. In addition, we found that various combinations of antiplatelet therapy with AC did not lead to an increased risk of gastrointestinal hemorrhage.

The American Society for Gastrointestinal Endoscopy (ASGE) guidelines recommend cessation of clopidogrel and AC prior to ERCP with EBS, although these agents can be continued prior to EPBD alone [35]. On the other hand, the European Society for Gastrointestinal Endoscopy (ESGE) has recommended that EPBD may be considered as an alternative to EBS, when AC therapies cannot be interrupted. As a result, the biliary endoscopist has been faced with the dilemma of potential cardiovascular and thromboembolic events, weighed against the risk of gastrointestinal hemorrhage in those requiring urgent ERCP, without robust data to support a decision. This led us to validate a new technique of $\mathrm{m}$-EBS + EPBD in this setting.

Prior studies have estimated that the incidence of gastrointestinal hemorrhage has been $1 \%$ to $5 \%$ for individuals undergoing EBS [11-14]. Presence of antiplatelet/AC has been demonstrated to be associated with an increased risk of gastrointestinal hemorrhage in those undergoing ERCP with EBS $[11,14$, 23-26]. As an alternative method for biliary intervention, EPBD has demonstrated similar efficacy and overall AE rates, with lower rates of gastrointestinal hemorrhage as compared to EBS $[6-8,14]$. Yet it is important to note that all studies excluded those on agents that would increase risk of post-procedural hemorrhage.

Conversely, it is also important to note that there was an estimated $5 \%$ to $7 \%$ risk of post-ERCP pancreatitis with EPBD alone. Previous prospective studies evaluated risk of post-ERCP pancreatitis after EPBD [7, 11,40-42]. Studies performed outside of the United States reported relatively low incidence of post-ERCP pancreatitis after EPBD alone. However, when studies evaluating EPBD alone have been reproduced in the United States, the incidence of post-ERCP pancreatitis was unacceptably high [15].

Our rationale for performing $m-E B S+E P B D$ in this setting was to reduce risk of bleeding when compared with EBS alone while avoiding the risk of post-ERCP pancreatitis reported with EPBD alone. Although we did not posses a direct comparative EPBD-alone group (on AC and/or antiplatelet therapy), the techniques of $m$-EBS + EPBD for our cohort had an incidence of post-ERCP pancreatitis lower than prior studies reported in the United States. In addition, the rate of post-procedural hemorrhage in our study was equivalent to data reported in the literature for patients undergoing EBS and who were not on antiplatelet/AC. The rate of bleeding was also lower than reported in studies evaluating patients at an increased risk of gastrointestinal bleeding after ERCP.

Regarding data on ERCP in patients who are at increased risk of post-procedural hemorrhage, retrospective studies have been performed in patients requiring ERCP who have coagulopathy associated with cirrhosis [27-30]. In 1 study, incidence of bleeding after EBS was significantly higher compared with EPBD (30\% v. 0\%, $P=0.009$ ) [29]. An additional study reported an overall $1 \%$ risk of gastrointestinal hemorrhage after ERCP in cirrhotics, $2 \%$ risk after EBS in those with "biliary indications," and $13 \%$ in those with "pancreatic indications" [30].

A retrospective study by Hamada, et al evaluated a large Japanese cohort of patients on antiplatelet agents (aspirin, clopidogrel and others) or AC (warfarin or dabigatran) who were undergoing either EBS or EPBD [32]. It is important to note that this study did not report the overall incidence of gastrointestinal hemorrhage, but rather severe gastrointestinal hemorrhage, ( $1 \%$ for EBS versus $3 \%$ for EBPD). A similar incidence of severe gastrointestinal hemorrhage was reported for those on $A C$ and clopidogrel. This study also showed that the ORs for severe gastrointestinal hemorrhage were significantly higher in those continuing antiplatelet therapy $(O R=4.4)$ and $A C(O R=$ 7.5) for EPBD. This risk of severe gastrointestinal hemorrhage in EPBD is in contradiction to prior literature, which has cited a reduced risk of gastrointestinal hemorrhage with EPBD compared to EBS alone [9-15]. This may be due to unreported non-severe gastrointestinal hemorrhage.

Among patients in our study who underwent m-EBS with EPBD while on AC, 2 experienced a delayed gastrointestinal hemorrhage ( 1 patient on aspirin + warfarin and 1 patient on aspirin + rivaroxaban). Both patients required endoscopic intervention and PRBC transfusion. There was no further gastrointestinal hemorrhage after endoscopic intervention at 90-day follow up. These patients contributed to a $4 \%$ risk of severe gastrointestinal hemorrhage in this unique population of patients on aspirin and AC. Overall, we found no increased risk of bleeding for those on therapy including AC, warfarin, NOACs, aspirin + clopidogrel + AC, and in aspirin + clopidogrel + NOAC.

The Hamada, et al, paper evaluated EBS alone for those on dabigatran, and did not evaluate other NOACs, such as apixaban and rivaroxaban, that are currently available in the United States [32]. Though our series had small numbers on NOACs, this is the first study to evaluate EPBD or m-EBS + EPBD on these medications, and the first to analyze the risk of gastrointestinal bleeding while on rivaroxaban and apixaban. Our study is also the first to evaluate combination therapy with antiplatelet agents and/or AC/NOACs.

Few trials have evaluated use of antiplatelet therapy in patients undergoing ERCP [23-26,31]. Of them, 1 reported a $24 \%$ risk of gastrointestinal hemorrhage in patients on aspirin therapy [23]. Subsequently, another held aspirin 1 week prior to ERCP and reported a $9.5 \%$ incidence of gastrointestinal hemorrhage after EBS [31]. There have also been 2 retrospective case series evaluating clopidogrel use while undergoing ERCP [23]. One of these series involving clopidogrel, one, found that $3 \%$ of their study population was on clopidogrel at the time of ERCP. This series demonstrated a $53 \%$ incidence of gastrointes- 
tinal hemorrhage. An additional series of 9 patients undergoing EBS on clopidogrel found no post-procedural gastrointestinal hemorrhage [23, 24]. To our knowledge no study has evaluated EPBD combination with m-EBS for those on clopidogrel.

Though one may theorize that the risk of gastrointestinal bleeding in our cohort was higher than in patients who would have undergone EPBD alone, it is important to again note that this rate was equivalent to those undergoing EBS, who were not on AC/antiplatelet agents and lower than incidences reported in prior series for patients on these agents. Also important is that the reported rate of bleeding after EPBD is not zero in the literature, thus it is possible that these 4 cases of post-procedural hemorrhage may have occurred regardless.

Limitations of our study included referral bias, as both centers involved were tertiary care centers, and its retrospective nature. A prospective trial evaluating ERCP in patients on AC and/or clopidogrel would be a useful addition to the literature in this field, as would comparison to a control group of patients undergoing EPBD alone while on such agents. However as m$E B S+E P B D$ has been common practice at both of our centers, we do not have data available evaluating EPBD alone in this setting. It may also be possible that the incidence of AEs was low in our study due to the mean size of our balloon dilation being 8 $\mathrm{mm}$, not considered to be a large EPBD (>12 mm). Despite this possible limitation, all EPBD balloon sizes were appropriately selected to match biliary ductal size. We also demonstrated calculus extraction in 48 of 49 patients with choledocholithiasis, thus high success using this technique. We also realized that, although patients were advised to return to the center that performed their procedure and had a phone call 24 hours after, some patients might have had complications that we could not detect. The strengths of this paper include its multicenter design and the use of this novel technique in a large number of ERCP in patients on AC and/or clopidogrel. This is also one of the largest series of its kind to evaluate clopidogrel, combination antiplatelet therapy, AC, and dabigatran. Our study is the first to evaluate rivaroxaban and apixaban therapy, and aspirin + clopidogrel + AC/NOACs in the setting of ERCP and EBS.

\section{Conclusion}

In conclusion, m-EBS with EPBD for patients on clopidogrel and/ or anticoagulants is an effective and safe therapy with an estimated incidence of gastrointestinal hemorrhage of $4 \%, 2 \%$ of which required repeat endoscopy or transfusion. Minimal-EBS + EPBD appears to be an acceptable alternative to conventional EBS or EPBD in the setting of urgent biliary decompression for patients with high cardiovascular/thromboembolic risk on clopidogel/AC.

\section{Competing interests}

Shaffer R. S. Mok, Murtaza Arif, Henry C. Ho and Harshit S. Khara have no conflicts of interest. David L Diehl is a consultant for Boston Scientific and Olympus. Adam B. Elfant is a consultant for Boston Scientific.

\section{References}

[1] Binmoeller KF, Schafer TW. Endoscopic management of bile duct stones. J Clin Gastroenterol 2001; 32: $106-118$

[2] Adler DG, Baron TH, Davilla RE et al. ASGE guidelines: the role of ERCP in diseases of the biliary tract. Gastrointest Endosc 2005; 62: 1-8

[3] Venu RP, Geenen JE. Overview of endoscopic sphincterotomy for common bile duct stone. Gastrointest Endosc Clin N Am 1991; 1: $3-26$

[4] Foutch G. Endoscopic management of large common bile duct stones. Am J Gastroenterol 1991; 86: 1561-1565

[5] Seitz JH, Bapaye A, Bohnacker S et al. Advances in therapeutic endoscopic treatment of common bile duct stones. World J Surg 1998; 22: $1133-1144$

[6] Minami A, Nakatsu T, Uchida N et al. Papillary dilation vs sphincterotomy in endoscopic removal of bile duct stones: a randomized trial with manometric function. Dig Dis Sci 1995; 40: 2550-2554

[7] Bergman J], Rauws EAJ, Fockens P et al. Randomized trial of endoscopic balloon dilation versus endoscopic sphincterotomy for removal of bile duct stones. Lancet 1997; 349: 1124-1129

[8] Ochi Y, Mukawa K, Kiyosawa K et al. Comparing the treatment outcomes of endoscopic papillary dilation and endoscopic sphincterotomy for removal of bile duct stones. J Gastroenterol Hepatol 1999; 14: $90-96$

[9] Stefanidis G, Karamanolis G, Viazis N et al. A comparative study of postendoscopic sphincterotomy complications with various types of electrosurgical current in patients with choledocholithiasis. Gastrointest Endosc 2003; 57: $192-197$

[10] Verma D, Kapadia A, Adler DG. Pure versus mixed electrosurgical current for endoscopic biliary sphincterotomy: a meta-analysis of adverse outcomes. Gastrointest Endosc 2007; 66: 283-290

[11] Freeman ML, Nelson DB, Sherman S et al. Complications of endoscopic biliary sphincterotomy. NEJM 1996; 335: 909-918

[12] Masci E, Toti G, Mariani A et al. Complications of diagnostic and therapeutic ERCP: a prospective multicenter study. Am J Gastroenterol 2001; 96: 417-423

[13] Loperfido S, Angelini G, Benedetti G et al. Major early complications from diagnostic and therapeutic ERCP: a prospective multicenter study. Gastrointest Endosc 1998; 48: 1- 10

[14] Zhao HC, He L, Zhou DC et al. Meta-analysis comparison of endoscopic papillary balloon dilatation and endoscopic sphincteropapillotomy. World J Gastroenterol 2013; 19: 3883-3891

[15] Baron TH, Harewood GC. Endoscopic balloon dilation of the biliary sphincter compared to endoscopic biliary sphincterotomy for removal of common bile duct stones during ERCP: a metaanalysis of randomized, controlled trials. Am J Gastroenterol 2004; 99: 1455 - 1460

[16] Kim HG, Cheon YK, Cho YD et al. Small sphincterotomy combined with endoscopic papillary large balloon dilation versus sphincterotomy. World J Gastroenterol 2009; 15: 4298-4304

[17] Guo SB, Meng H, Duan Z] et al. Small sphincterotomy combined with endoscopic papillary large balloon dilation vs sphincterotomy alone for removal of common bile duct stones. World J Gastroenterol 2014; 20: $17962-17969$

[18] Bo QJ, Hua XL, Min CT et al. Small Endoscopic Sphincterotomy plus Large-Balloon Dilation for Removal of Large Common Bile Duct Stones during ERCP. Pak J Med Sci 2013; 29: 907 -912

[19] Teoh AY, Cheung FK, Hu B et al. Randomized trial of endoscopic sphincterotomy with balloon dilation versus endoscopic sphincterotomy alone for removal of bile duct stones. Gastroenterol 2013; 144 : $341-345$

[20] Williams DO, Abbott JD, Kip KE. DEScover Investigators. Outcomes of 6906 patients undergoing percutaneous coronary intervention in the 
era of drug-eluting stents: report of the DEScover Registry. Circulation 2006; 114: 2154-2162

[21] lakovou I, Schmidt T, Bonizzoni E et al. Incidence, predictors, and outcome of thrombosis after successful implantation of drug-eluting stents. JAMA 2005; 293: 2126-2130

[22] Mauri L, Hsieh WH, Massaro JM et al. Stent thrombosis in randomized clinical trials of drug-eluting stents. N Engl J Med 2007; 356: $1020-$ 1029

[23] Hussain N, Alsulaiman R, Burtin P et al. The safety of endoscopic sphincterotomy in patients receiving antiplatelet agents: a case-control study. Aliment Pharmacol Ther 2007; 25: 579-584

[24] Samie AA, Stumpf M, Sun R et al. Biliary-Pancreatic Endoscopic and Surgical Procedures in Patients under Dual Antiplatelet Therapy: A Single-Center Study. Clin Endosc 2013; 46: 395 - 398

[25] Abdel Samie AA, Sun R, Vohringer $U$ et al. Safety of endoscopic sphincterotomy in patients under dual antiplatelet therapy. Hepatogastroenterology 2013; 60: 659-666

[26] Onal IK, Parlak E, Akdogan M et al. Do aspirin and non-steroidal antiinflammatory drugs increase the risk of post-sphincterotomy hemorrhage - a case-control study. Clin Res Hepatol Gastroenterol 2013; 37: $171-176$

[27] Kawabe T, Komatsu Y, Tada M et al. Endoscopic papillary balloon dilation in cirrhotic patients: removal of common bile duct stones without sphincterotomy. Endoscopy 1996; 28: 694-698

[28] Komatsu Y, Kawabe T, Toda $\mathrm{N}$ et al. Endoscopic papillary balloon dilation for the management of common bile duct stones: experience of 226 cases. Endoscopy 1998; 30: $12-17$

[29] Park DH, Kim MH, Lee SK et al. Endoscopic sphincterotomy vs. endoscopic papillary balloon dilation for choledocholithiasis in patients with liver cirrhosis and coagulopathy. Gastrointest Endosc 2004; 60: $180-185$

[30] Adler DG, Haseeb A, Francis G et al. Efficacy and safety of therapeutic ERCP in patients with cirrhosis: a large multicenter study. Gastrointestinal Endosc 2015; 83: 353-359

[31] Hui CK, Lai KC, Yuen MF et al. Does withholding aspirin for one week reduce the risk of post-sphincterotomy bleeding? Aliment Pharmacol Ther 2002; 16: 929-936
[32] Hamada T, Yasunaga H, Nakai Y et al. Bleeding after endoscopic sphincterotomy or papillary balloon dilation among users of antithrombotic agents. Endoscopy 2015; 47: $997-1004$

[33] Hassan C, Zullo A. Antiplatelet therapy and endoscopic procedures: eyes wide shut? Endosc Int Open 2015; 3: E179-180

[34] Douketis JD, Spyropoulos AC, Spencer FA et al. Perioperative management of antithrombotic therapy: Antithrombotic Therapy and Prevention of Thrombosis, 9th ed: American College of Chest Physicians Evidence-Based Clinical Practice Guidelines. Chest 2012; 141: e326S-350S

[35] Acosta RD, Abraham NS, Chandrasekhara V et al. The management of antithrombotic agents for patients undergoing Gl endoscopy. Gastrointest Endosc 2016; 83: 3-16

[36] Boustiere C, Veitch A, Vanbiervliet G et al. Endoscopy and antiplatelet agents. European Society of Gastrointestinal Endoscopy (ESGE) Guideline. Endoscopy 2011; 43: 445-461

[37] Baron TH, Kamath PS, McBane RD et al. Management of antithrombotic therapy in patients undergoing invasive procedures. $N$ Engl J Med 2013; 368: 2113-2124

[38] Liao WC, Lee CT, Chang CY et al. Randomized trial of 1-minute versus 5-minute endoscopic balloon dilation for extraction of bile duct stones. Gastrointest Endosc 2010; 72: 1154 - 1162

[39] Cotton PB, Eisen GM, Aabakken L et al. A lexicon for endoscopic adverse events: report of an ASGE workshop. Gastrointest Endosc 2010; 71: $446-454$

[40] Vlavianos P, Chopra K, Mandalia S et al. Endoscopic balloon dilatation versus endoscopic sphincterotomy for the removal of bile duct stones: a prospective randomized trial. Gut 2003; 52: 1165-1169

[41] Fujita N, Maguchi H, Komatsu Y et al. Endoscopic sphincterotomy and endo- scopic papillary balloon dilation for bile duct stones: a prospective randomized controlled multicenter trial. Gastrointest Endosc 2003; 57: $151-155$

[42] Arnold JC, Benz C, Martin WR et al. Endoscopic papillary balloon dilation vs. sphincterotomy for removal of common bile duct stones: a prospective randomized pilot study. Endoscopy 2001; 33: 563-567 